\title{
Adsorption of Basic and Acidic Dyes onto Agricultural Wastes
}

\author{
Okorocha J. Nnaemeka ${ }^{1, a *}$, Okoji J. Josphine ${ }^{2, b}$, Osuji Charles ${ }^{3, c}$ \\ ${ }^{1,2,3}$ Department of Chemistry, Federal University of Technology, Owerri, Imo State, Nigeria \\ aemybeck@yahoo.com, 'lajoe4real@yahoo.com, 'charlesdon05@yahoo.com
}

\section{Keywords: Adsorption, Almond leaves powder, Crystal violet, Congo red, Isotherms, Kinetics}

\begin{abstract}
The potential of almond leaves powder, (ALP) for the removal of Crystal violet (CV) and Congo red (CR) dyes from aqueous solution was investigated. The adsorbent (ALP) was characterized by FTIR and SEM analysis. Batch adsorption studies were conducted and various parameters such as contact time, adsorbent dosage, initial dye concentration, $\mathrm{pH}$ and temperature were studied to observe their effects in the dyes adsorption process. The optimum conditions for the adsorption of $\mathrm{CV}$ and CR dyes onto the adsorbent (ALP) were found to be: contact time (100mins), $\mathrm{pH}(10.0)$, temperature (343K) for an initial CV dye concentration of $50 \mathrm{mg} / \mathrm{L}$ using adsorbent dose of $1.0 \mathrm{~g}$ and contact time (100mins), $\mathrm{pH}(2.0)$, temperature (333K) for an initial CR dye concentration of $50 \mathrm{mg} / \mathrm{L}$ using adsorbent dose $1.0 \mathrm{~g}$ respectively. The experimental equilibrium adsorption data fitted best and well to the Freundlich isotherm model for both CV and CR dyes adsorption. The maximum adsorption capacity of ALP was found to be $22.96 \mathrm{mg} / \mathrm{g}$ and $7.77 \mathrm{mg} / \mathrm{g}$ for the adsorption of $\mathrm{CV}$ and CR dyes respectively. The kinetic data conformed to the pseudosecond-order kinetic model. Thermodynamic quantities such as Gibbs free energy $\left(\Delta \mathrm{G}^{0}\right)$, enthalpy $\left(\Delta \mathrm{H}^{0}\right)$ and entropy $\left(\Delta \mathrm{S}^{0}\right)$ were evaluated and the negative values of $\Delta \mathrm{G}^{0}$ obtained for both dyes indicate the spontaneous nature of the adsorption process while the positive values of $\Delta \mathrm{H}^{0}$ and $\Delta \mathrm{S}^{0}$ obtained indicated the endothermic nature of the adsorption and increased randomness during the adsorption process respectively for the adsorption of CV and CR onto ALP. Based on the results obtained such as good adsorption capacity, rapid kinetics, and its low cost, ALP appears to be a promising adsorbent material for the removal of $\mathrm{CV}$ and $\mathrm{CR}$ dye stuff from aqueous media.
\end{abstract}

\section{Introduction}

Colour is considered as the first pollutant to be identified in waste water and it is mostly caused by effluents discharged form dyeing industries such as paper, rubber, leather, cosmetics, textile, pharmaceuticals, plastics and food industries [1]. More than 10,000 dyes are commercially available and more than $7 \times 10^{5}$ tonnes per year of these dyes are produced in the world for the textile industry alone [2]. Most of the dyes used in the industry are synthetic; having complex aromatic molecular structures that make them more stable and less biodegradable [3]. The manufacture and use of synthetic dyes for dyeing fabrics has become an industry solid. It is estimated that about $20 \%$ of the total amount of dyes produced and used by these industries in a year is unloaded in to the industry waste without previous treatment [3].

However, their use has become a matter of serious concern to environmentalist. Synthetic dyes are highly toxic, causing negative effects on all life forms because they present sulphur, naphtol, vat dyes, nitrates, acetic acid, surfactants, enzymes chromium compounds and metals such as copper, arsenic, lead, cadmium, mercury, nickel, cobalt and certain auxillary chemicals [4].

The crystal violet (CV) dye is a synthetic cationic dye and transmits violet colour in aqueous solution. It is also known as Basic Violet 3, gentian violet and methyl violet $10 \mathrm{~B}$, belonging to the group of triarylmethane. This dye is used extensively in the textile industries for dying cotton, wool, silk, nylon, in manufacture of printing inks and also the biological stain, a dermatological agent in veterinary medicine. The CV is toxic and may be absorbed through the skin causing irritation and is harmful by inhalation and ingestion. In extreme cases, CV can lead to kidney failure, severe eye irritation leading to permanent blindness and cancer. Therefore, removal of this dye from water and wastewater is highly essential [4]. 
Congo red (CR) is a benzidine-based azo dye with complex chemical structure, high solubility in aqueous solution and it is persistent once it is discharged into natural environment. Congo red mainly occurs in effluents discharged from textile, paper, printing, leather industries etc., and during dyeing operation; about $15 \%$ of it ends up in wastewaters $[5,6]$. It exists as a brownish -red crystal and is stable in air with a solubility of $1 \mathrm{~g} / 30 \mathrm{ml}$ in water. It is an anionic acid dye used as a laboratory aid in testing for free hydrochloric acid in gastric contents, in diagnosis of amyloidosis, as an indicator of $\mathrm{pH}$. It has a strong affinity to cellulose fibers and thus is employed in textile industries. It is a dervative of benzidine and napthoic acid and metabolizes to carcinogenic products. It is investigated as a mutagen and reproductive effector. It is a skin, eye and gastrointestinal irritant. It may affect blood factors such as clothing and induce somnolence and respiratory problems [6].

Diverse methods of treatment exploited through the years by researchers and industries for removing dyes and colour include physicochemical, chemical, and biological methods, such as flocculation, coagulation, precipitation, adsorption, membrane filtration, electrochemical techniques, ozonation, and fungal decolorization [7, 8]. However, due to the fact that effluents contain different dyes, and these dyes contain complex structures, is very difficult to treat using conventional methods [4].

The adsorption is one of the most effective processes of advanced wastewater treatment, which industries employ to reduce hazardous pollutants present in the effluents. This is a wellknown and superior technique to other processes for removal of dyes from aqueous solutions worldwide due to initial cost, operating conditions and simplicity of design [9]. Currently, the most common procedure involves the use of activated carbon as adsorbent for this purpose by offering greater adsorption capacities. However, due to their relatively high cost, many lower-cost adsorbents have been investigated as adsorbent for removing contaminants from wastewater. The low cost adsorbents can be made from waste materials, thus collaborating with the environment and also getting economic advantages. A wide variety of low cost adsorbents have been prepared from different materials utilizing industrial, biomass, and municipal wastes [10].

These days, there are numerous low cost, commercially available adsorbents for dye removal. However, the adsorption efficiencies of these adsorbents are not very high. In view of these limitations, there have been constant search for alternative, low cost and easily available adsorbents with high efficiencies for removal of dyes from wastewater or aqueous solution. Almond (Prunus dulcis) leaves from the Almond tree constitute a nuisance as they liter the environment as waste materials. The usage of these waste materials for adsorption process could result in waste utilization and minimization leading to tremendous cost saving.

Therefore, the potential of almond leaves powder was explored under batch conditions. The effect of several parameters such as contact time, adsorbent dosage, initial dyes concentration, $\mathrm{pH}$ and temperature were investigated in the experimental study. The adsorption equilibrium isotherm models, kinetic models and thermodynamic parameters related with the process were studied and reported.

\section{Literature Review}

Spent tea leaves as low-cost adsorbent have been investigated by Bajpai and Jain [11] for the removal of basic dye (Crystal violet) from aqueous solutions at different temperature in batch experiments. The adsorption was found to be favoured at higher temperature. The order to fitness of various isotherm models, when applied on equilibrium uptake data, was found to be Langmuir $=$ Temkin > Freundlich. The values of Langmuir constants, $Q_{\max }(\mathrm{mg} / \mathrm{g})$ and $\mathrm{b}(\mathrm{l} / \mathrm{mol})$ are found to be 114.94 and $80457.6 ; 185.18$ and $52795.2 ; 285.71$ and 41983.2 at $25^{\circ}, 37^{\circ}$ and $50^{\circ} \mathrm{C}$ respectively. Thermodynamic quantities, i.e. $\Delta \mathrm{G}^{\mathrm{o}}, \Delta \mathrm{H}^{\mathrm{o}}$ and $\Delta \mathrm{S}^{\mathrm{o}}$ were also evaluated. The negative $\Delta \mathrm{G}^{\mathrm{o}}$ values indicated spontaneous nature of the adsorption process.

Alshabanat et al. [12] examined the adsorption of Crystal violet (CV) onto date palm fibers (DPFs) in aqueous solution at $25^{\circ} \mathrm{C}$. The experimental maximum adsorption capacity value was found to be $0.66 \times 10^{-6} \mathrm{mg} / \mathrm{g}$. The percentage removal of CV dye by adsorption onto DPF at different 
$\mathrm{pH}$ and temperatures showed that these factors play a role in the adsorption process. Thermodynamic analysis was performed, and the negative values of $\Delta G^{\mathrm{o}}$ indicate spontaneous adsorption. The negative value of $\Delta H^{\circ}$ indicates that the interaction between $\mathrm{CV}$ and DPF is exothermic, and the positive value of $\Delta S^{\circ}$ indicates good affinity between DPF and CV. The kinetic data were fitted to a pseudo-second-order model.

Adsorption of Congo red (CR) from aqueous solution using dried roots of Eichhornia crassipes was studied by Wanyonyi et al. [13]. Batch experiments were carried out for sorption kinetics and isotherms. Experimental results obtained showed that adsorption process was highly dependent on contact time, adsorbent dosage, initial dye concentration and particle size. The sorption equilibrium for Congo red dye by E. crassipes (roots) was reached within 90 minutes and adsorption efficiency of up to $96 \%$ achieved. The sorption kinetics followed a pseudo-second-order kinetic model while Freundlich isotherm model was best applicable for obtaining the equilibrium parameters.

Nagda and Ghole [14] investigated the biosorption of congo red by hydrogen peroxide treated tendu (Diospyros melanoxylon) waste. Comparison was done on the extent of biosorption between untreated and treated forms of the adsorbents. It was reported that the adsorption occurred very fast initially and attained equilibrium within 60 minutes at $\mathrm{pH}=6.2$ and the equilibrium attained faster after modification. The data fitted Freundlich isotherm model for treated ones while it fitted Langmuir for untreated ones and the maximum adsorption capacity was 46.95 and $134.4 \mathrm{mg} / \mathrm{g}$ for untreated and treated ones respectively. The kinetic data followed pseudo-second order rate equation.

Other low-cost adsorbents investigated and found efficient includes: the indian jujuba seeds which yielded adsorption capacity of $55.56 \mathrm{mg} / \mathrm{g}$ for Congo Red dye [15], jute stick powder also yielded adsorption capacity of $35.7 \mathrm{mg} / \mathrm{g}$ for Congo Red dye [16], etc.

\section{Materials and Methods}

\section{Materials}

Almond leaves powder, (ALP) (adsorbent), Congo red (CR) and Crystal violet (CV) dyes (adsorbates), Hydrochloric acid $(\mathrm{HCl})$ and Sodium Hydroxide $(\mathrm{NaOH})$, Distilled water, Conical flask, and beakers, Measuring cylinders and funnels, Filter papers (Whatman NO.1), Digital pH meter, Electrical shaker, Electronic weighing balance, Thermostatic water bath.

\section{Preparation of Adsorbent}

Almond leaves were collected from Naze, Owerri north local government of Imo state, Nigeria. The almond leaves were washed thoroughly with distilled water to remove sand, dirt and other impurities present. The leaves were sundried for several days until all moistures were removed. It was then grounded in a steel mill and sieved in a sieve shaker of particle size of $150 \mu \mathrm{m}$. The almond leaves powder that passed through the sieve was used as adsorbent without any further pretreatment. It was labeled ALP (almond leaves powder) and finally stored in an airtight container for further use.

\section{Preparation of CV and CR Dye Solutions}

Analytical grade $\mathrm{CV}$ dye (molecular formular: $\mathrm{C}_{25} \mathrm{H}_{30} \mathrm{~N}_{3} \mathrm{Cl}$, molecular weight: 407.98, $\lambda$ max $=590 \mathrm{~nm}$ ). Analytical grade $\mathrm{CR}$ dye (molecular formular: $\mathrm{C}_{32} \mathrm{H}_{22} \mathrm{~N}_{6} \mathrm{O}_{6} \mathrm{Cl} \mathrm{S}_{2} \mathrm{Na}_{2}$, molecular weight: $696.68, \lambda \max =500 \mathrm{~nm}$ ) both dyes were obtained from chemical laboratory in FUTO and used without purification. A stock solution of $\mathrm{CV}$ dye of concentration $1000 \mathrm{mg} / \mathrm{L}$ was prepared by dissolving $1 \mathrm{~g}$ of $\mathrm{CV}$ dye powder in $1 \mathrm{~L}$ of distilled water. A stock solution of $\mathrm{CR}$ dye of concentration $1000 \mathrm{mg} / \mathrm{L}$ was also prepared by dissolving $1 \mathrm{~g}$ of CR dye powder in $1 \mathrm{~L}$ of distilled water. Experimental working solutions of desired concentration were obtained by appropriate dilution of the stock solutions. 


\section{Adsorbent Characterization}

Fourier transform infra-red (FTIR) spectrophotometer was used to identify the different functional groups available on the adsorbent sites. The FTIR of the adsorbent was taken before adsorption using FTIR spectrophotometer (Shimadzu-8400S). The adsorbent was encapsulated with $\mathrm{KBr}$ spectroscopy grade and by introducing the mix in a piston's cell of a hydraulic pump with compression pressure $15 \mathrm{KPa} / \mathrm{cm}^{2}$; the solid transluscent disk was obtained. The FTIR spectrum was then recorded within the wave number range $4000-500 \mathrm{~cm}^{-1}$. In addition, surface morphology and texture of the adsorbent was analyzed using scanning electron microscope (SEM) (ModelPHENOM ProX). Prior to scanning, some quantity of the adsorbent was placed on a double adhesive sticker placed in a sputter machine for $5 \mathrm{sec}$; this gave the adsorbent a conductive property. Sample (adsorbent) stud was fixed on a charge reduction sample holder, and then was charged in the SEM machine.

\section{Batch Adsorption Experiments}

Batch adsorption of CV and CR dye onto the adsorbent (ALP) was conducted in a $250 \mathrm{ml}$ airtight Erlenmeyer flask containing $100 \mathrm{ml}$ of known concentration of dye solution and an accurately weighed amount of the adsorbent. The mixtures in the flasks were agitated on a rotary shaker operating at a constant speed of $100 \mathrm{rpm}$. The effect of contact time $(10,20,40,60,80,100$ \& $120 \mathrm{~min})$, adsorbent dosage $(0.5,1,2,3 \& 4 \mathrm{~g} / \mathrm{L})$, initial CV dye concentration $(25,50,75,100 \&$ $120 \mathrm{mg} / \mathrm{l}), \mathrm{pH}(2,4,6,8 \& 10)$ and temperature $(303,313,323,333 \& 343 \mathrm{~K})$ were evaluated. The flask containing the samples were withdrawn from the shaker at predetermined time intervals, filtered and the final concentrations of CV dye in the supernatant solutions were analyzed using the UV-visible spectrophotometer (Jenway 6305). The entire batch adsorption procedure was also carried out using $\mathrm{CR}$ dye. The $\mathrm{pH}$ of the solutions were adjusted using $1 \mathrm{M} \mathrm{HCl}$ or $\mathrm{NaOH}$. All experimental studies were carried out in triplicates and the mean values reported. The amount of equilibrium uptake of dye was determined using

$$
\begin{gathered}
\text { Dye removal }(\%)=\frac{C_{0}-C_{e}}{C_{0}} \times 100, \\
q_{e}=\left(C_{0}-C_{e}\right) \frac{V}{W} .
\end{gathered}
$$

where $q_{e}$ is the amount of dye taken up by the adsorbent at equilibrium $(\mathrm{mg} / \mathrm{g}), \mathrm{C}_{\mathrm{o}}$ is the initial dye concentration $(\mathrm{mg} / \mathrm{L}), \mathrm{C}_{\mathrm{e}}$ is the dye concentration at equilibrium $(\mathrm{mg} / \mathrm{L}), M$ is the mass of the adsorbent $(\mathrm{g})$, and $V$ is the volume of the solution, (L).

\section{Results and Discussion}

\section{Characterization of the ALP}

The FTIR spectrum of ALP before adsorption was analyzed to determine the vibration frequency changes in their functional groups and is shown in Fig. 1. Various peaks were observed at $3453.34 \mathrm{~cm}^{-1}$ (due to $\mathrm{O}-\mathrm{H}$ stretch, $\mathrm{H}$ - bonded), $2388.92 \mathrm{~cm}^{-1}$ (due to $\mathrm{N}-\mathrm{H}$ bond), $2267.40 \mathrm{~cm}^{-1}$ (due to $\mathrm{C} \equiv \mathrm{C}$ bond, or $\mathrm{C} \equiv \mathrm{N}$ ), $1647.26 \mathrm{~cm}^{-1}$ (due to $\mathrm{C}=\mathrm{C}$ bond), $1437.98 \mathrm{~cm}^{-1}$ (due to symmetrical aliphatic bonding of $\mathrm{CH}_{3}$ ), $1187.23 \mathrm{~cm}^{-1}$ (due to $\mathrm{C}-\mathrm{N}$ bond) $1034.84 \mathrm{~cm}^{-1}$ (due to $\mathrm{C}-\mathrm{O}$ bond), $641.35 \mathrm{~cm}^{-1}$ (due to $\mathrm{C}-\mathrm{Cl}$ bond), [17].

Also, Fig. 2, shows the SEM image of ALP. It can be observed from Fig. 2, that the external surface of ALP is very rough, irregular and contains pores. 


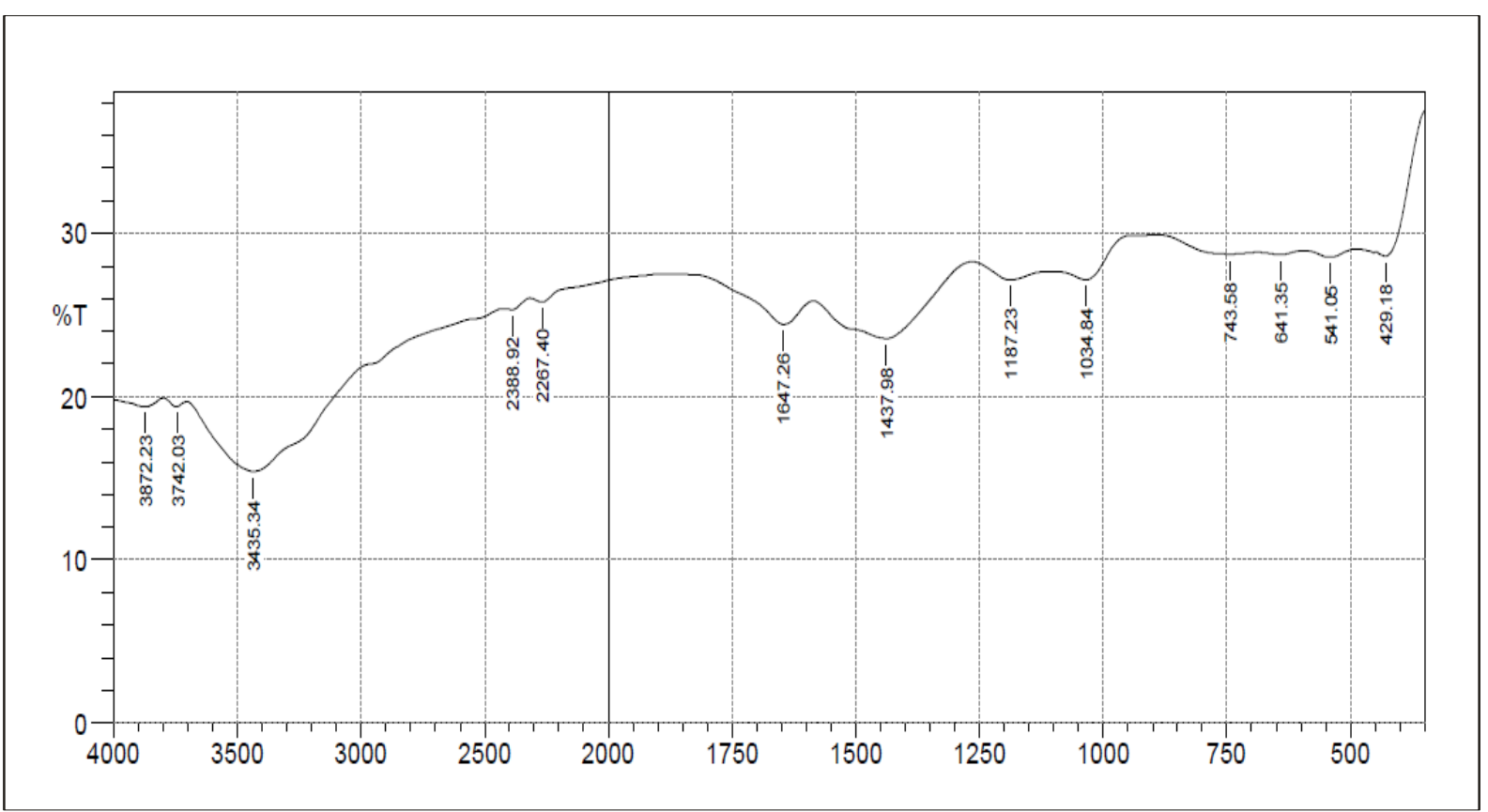

Fig. 1: FTIR spectra of ALP

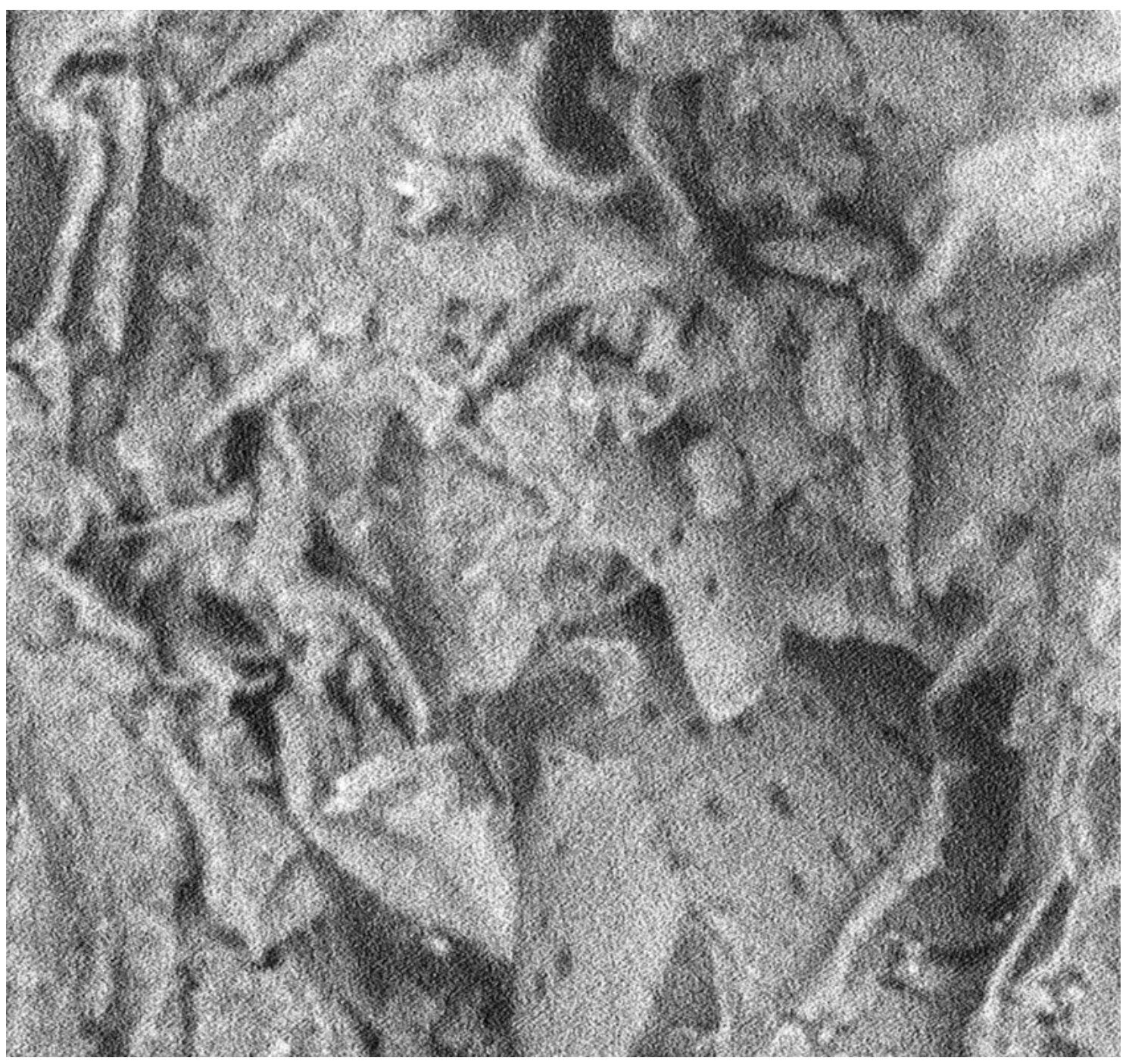

Fig. 2: SEM image of ALP at 1500x 


\section{Effect of Contact Time}

The effect of contact time on the removal of CV and CR dyes by ALP is depicted in Fig. 3. It is observed that the extent of adsorption of both dyes was rapid at the initial stages and becomes slow in later stages until equilibrium was achieved. It can be inferred from the rapid sorption rate at the early stages that there were abundance of active sites on the external surface of ALP which resulted in the rapid CV and CR dye removal. The final CV and CR dyes concentration did not vary appreciably after $100 \mathrm{~min}$ from the start of adsorption process. It indicates that equilibrium was assumed to be achieved after $100 \mathrm{~min}$ for the adsorption of CV and CR dye by ALP. This is attributed to the saturation of the active sites on ALP adsorbent which do not allow further adsorption to take place [18].

\section{Effect of Adsorbent Dosage}

The effect of adsorbent (ALP) dosage on the removal of CV and CR dyes is depicted in Fig. 4. The result revealed that the removal efficiency of CV and CR dye increased with increase in adsorbent dosage. This observation can be attributed to the fact that the number of active sites on ALP surface increased with the increase in the adsorbent dosage which led to increase in the dyes removal [19].

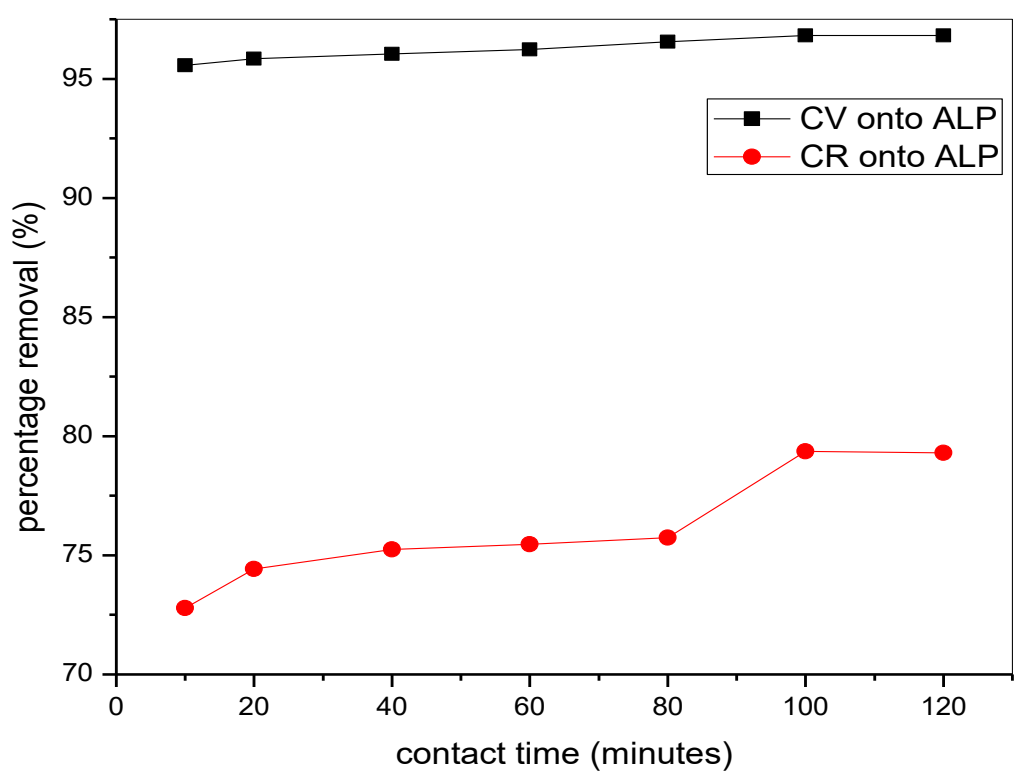

Fig. 3: Effect of contact time on the percentage removal of CV and CR onto ALP 


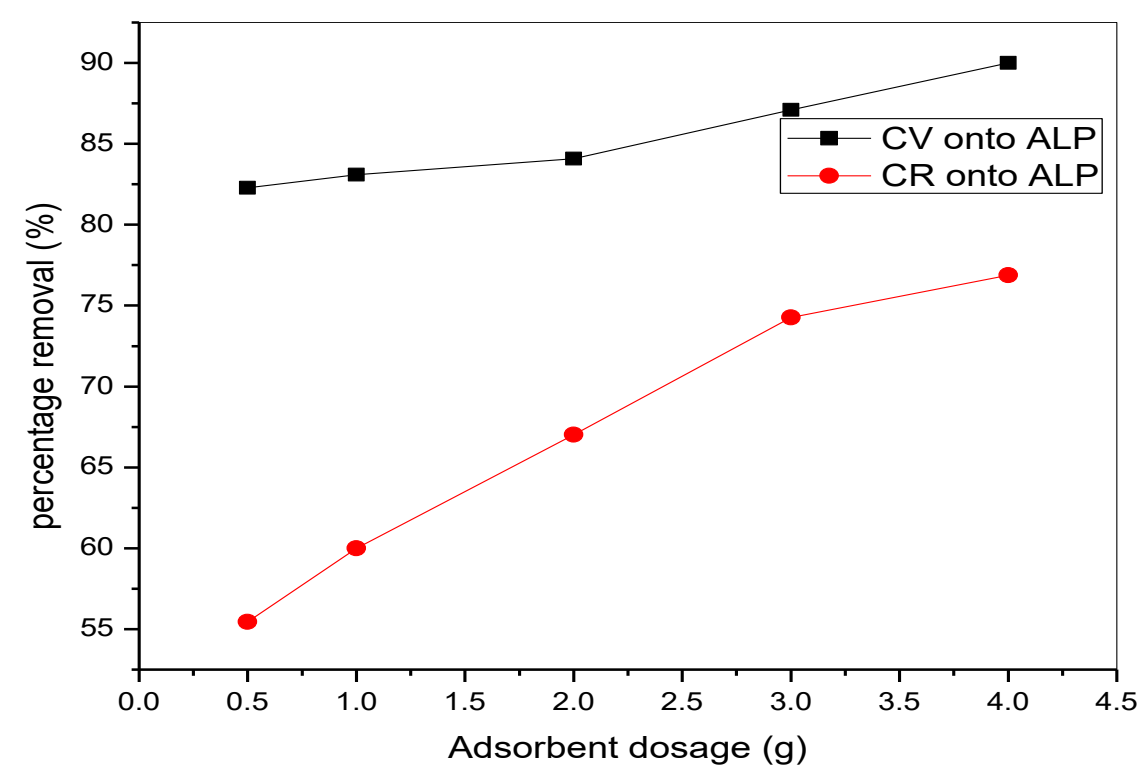

Fig. 4: Effect of adsorbent dosage on the percentage removal of CV and CR onto ALP

\section{Effect of Initial Dye Concentration}

The effect of initial dye concentration on the removal of CV and CR dyes is depicted in Fig. 5. It can be observed that the removal efficiency of CV and CR dye onto ALP decreased from $94.75 \%$ to $96.25 \%$ and 86.04 to $92.0 \%$ respectively as the initial concentration increased from $25 \mathrm{mg} / \mathrm{L}$ to $125 \mathrm{mg} / \mathrm{L}$. This observation can be attributed mainly to the fact that, for a given mass of adsorbent, the amount of dye it can adsorb is fixed. Thus, the higher the concentration of the dye the smaller the percentage it can remove [10]. Furthermore, the equilibrium adsorption capacity increased with increase in initial dye concentration (figure not shown). This is attributed to the fact that increasing dye concentration increases the driving force to overcome all mass transfer resistances of the $\mathrm{CV}$ and $\mathrm{CR}$ between the aqueous and solid phase, leading to an increase in equilibrium adsorption capacity $[19,20]$.

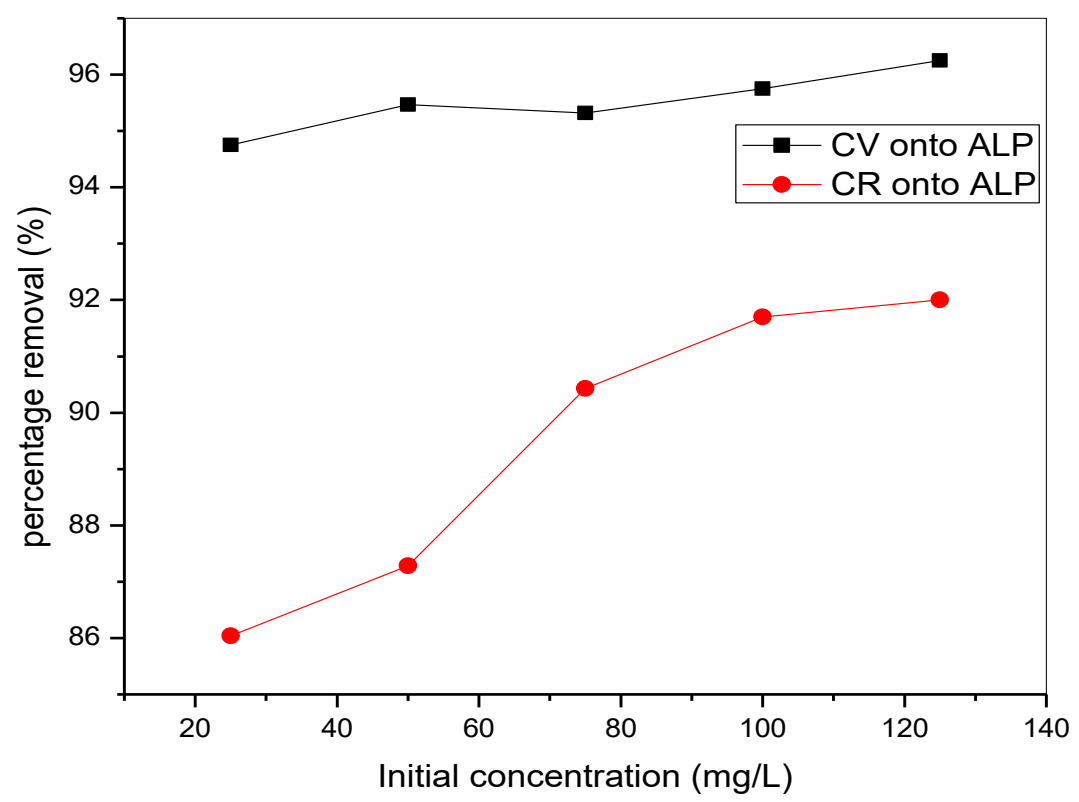

Fig. 5: Effect of initial concentration on the percentage removal of CV and CR onto ALP 


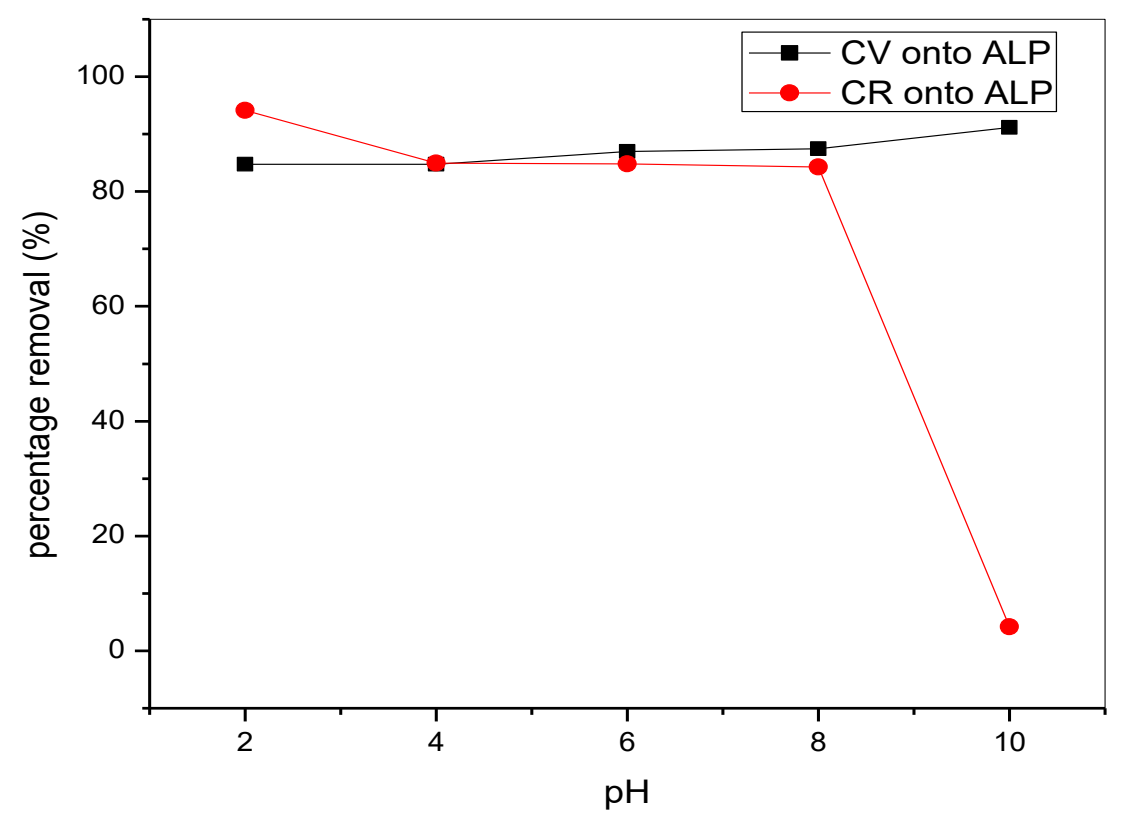

Fig. 6: Effect of $\mathrm{pH}$ on the percentage removal of $\mathrm{CV}$ and $\mathrm{CR}$ onto ALP

\section{Effect of pH}

The initial $\mathrm{pH}$ of dye solution has greater significance than the final $\mathrm{pH}$ of the solution in adsorption reaction. The influence of $\mathrm{pH}$ on the adsorption of $\mathrm{CV}$ and $\mathrm{CR}$ onto ALP is illustrated in Fig. 6. It was observed that the percentage removal of $\mathrm{CV}$ dye increased while the percentage removal of $\mathrm{CR}$ dye decreased as the initial $\mathrm{pH}$ of the solution increased from 2 to 10 . Optimum removal efficiency was obtained at $\mathrm{pH}$ of 10 and 2 for the adsorption of $\mathrm{CV}$ and $\mathrm{CR}$ dye respectively. The increase in removal efficiency of $\mathrm{CV}$ dye with increase in $\mathrm{pH}$ is basically due to the fact that at higher $\mathrm{pH}$ values, the positive charges $\left(\mathrm{H}^{+}\right)$at the solution interphase decreases and the adsorbent surface is more negatively charged, thus enhancing adsorption of more amount of the cations of the $\mathrm{CV}$ dye [21]. While the increase in removal efficiency with decrease in $\mathrm{pH}$ for the adsorption of CR can be attributed to the fact that at low $\mathrm{pH}$ values of the solution, the presence of excess hydrogen ion or positive charges at the solution interface increases, hence the ALP surface becomes more positively charged leading to the adsorption of more anions of CR dye.

\section{Effect of Temperature}

The influence of temperature on the removal of efficiency of CV and CR dyes by ALP is illustrated in Fig. 7. It can be observed that increase in temperature resulted in increase in removal efficiency of both CV and CR dyes. This increase in removal efficiency of CV and CR dyes by ALP with increase in temperature can be attributed to the fact that an increase in temperature may reduce the viscosity of the solution and increase the rate of diffusion of the adsorbate molecules across the external boundary layer and in the internal pores of the adsorbent (ALP) leading to more $\mathrm{CV}$ and CR removal [22]. Optimum adsorption was observed at temperature of $70^{\circ} \mathrm{C}$ and $60^{\circ} \mathrm{C}$ for adsorption of $\mathrm{CV}$ and $\mathrm{CR}$ dyes respectively. 


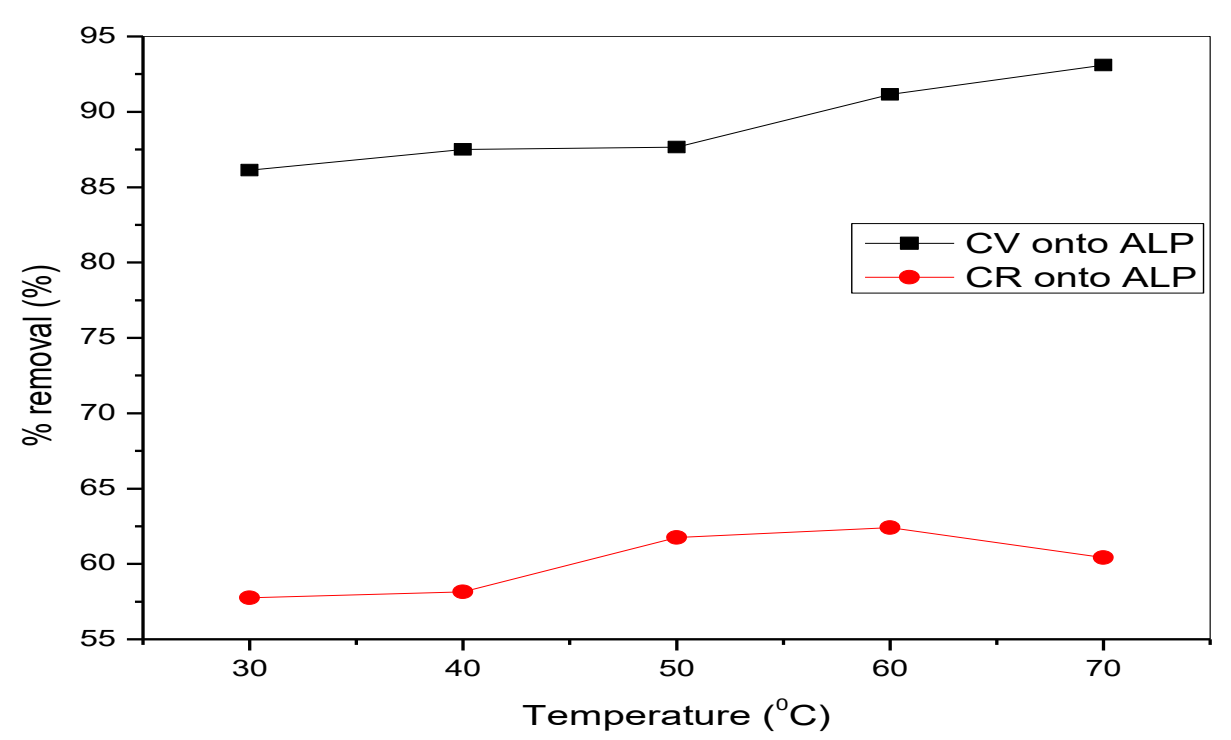

Fig. 7: Effect of temperature on the percentage removal of CV and CR onto ALP

\section{Adsorption Isotherms}

Two adsorption isotherm models have been applied to describe the relationship between the $\mathrm{CV}$ and CR dye concentration in the bulk solution and that on the ALP's surface namely, the Langmuir and Freundlich isotherm models.

The linear form of Langmuir equation is given as

$$
\frac{C_{e}}{q_{e}}=\frac{1}{q_{m} K_{l}}+\frac{C_{e}}{q_{m}},
$$

where $q_{e}(\mathrm{mg} / \mathrm{g})$ is the amount of dye adsorbed at equilibrium, $q_{m}(\mathrm{mg} / \mathrm{g})$, the amount of dye adsorbed when saturation is attained, $C_{e}$ is the equilibrium dye concentration $(\mathrm{mg} / \mathrm{L})$ and $K_{l}$ is Langmuir constant related to the binding strength of dye onto the adsorbent. The essential features of the Langmuir isotherm may be expressed in terms of equilibrium parameter $R_{l}$, which is a dimensionless constant referred to as separation factor $[10,23]$ :

$$
\mathrm{R}_{\mathrm{l}}=\frac{1}{1+\mathrm{K}_{\mathrm{l}} \mathrm{C}_{\mathrm{o}}}
$$

The value of $R_{l}$ indicates the type of the isotherm to be either unfavourable $\left(R_{l}>1\right)$, linear $\left(\mathrm{R}_{\mathrm{l}}=1\right)$, favourable $\left(0<\mathrm{R}_{\mathrm{l}}<1\right.$ or irreversible $\left(\mathrm{R}_{\mathrm{l}}=0\right)$

The linearized form of Freundlich equation is expressed as

$$
\log \mathrm{q}_{\mathrm{e}}=\log \mathrm{K}_{\mathrm{f}}+\frac{1}{\mathrm{n}} \log \mathrm{C}_{\mathrm{e}}
$$

where $K_{f}$ and $n$ are the Freundlich constants that represent adsorption capacity and intensity (strength) of adsorption respectively. 


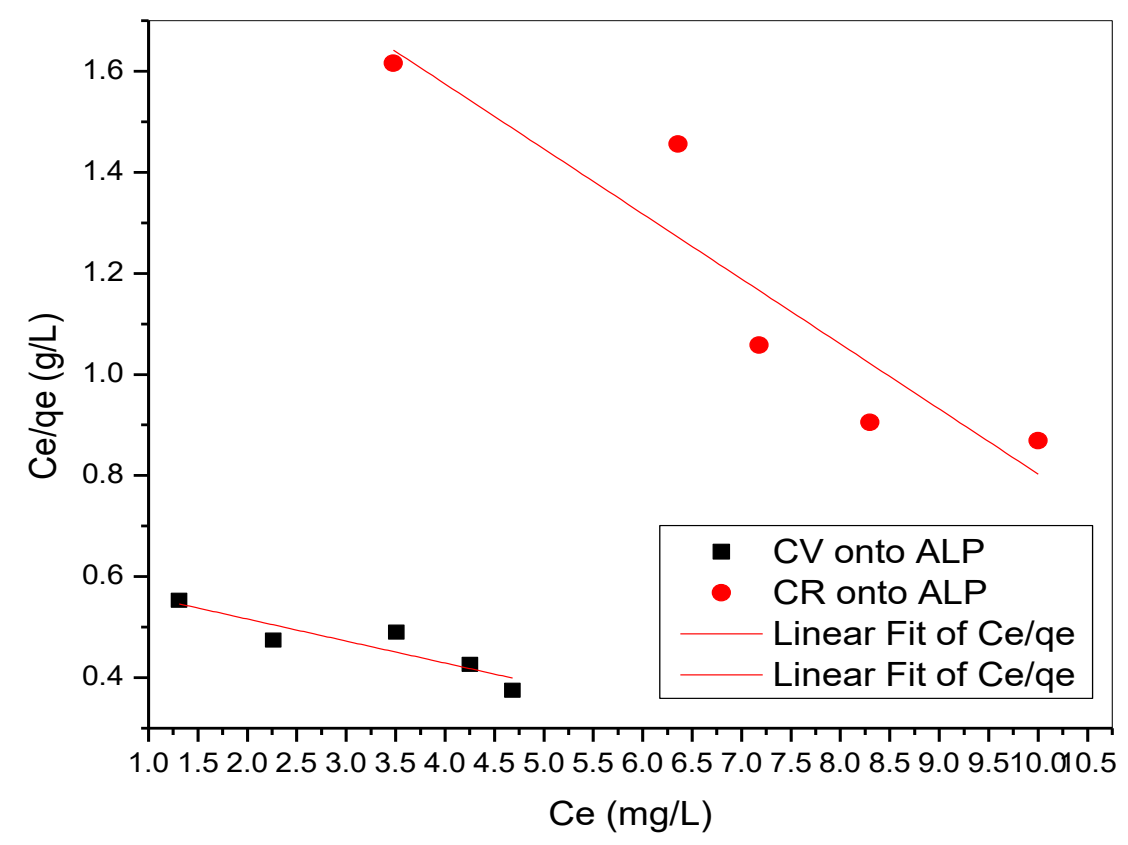

Fig. 8: Langmuir isotherm plot for the adsorption of CV and CR onto ALP

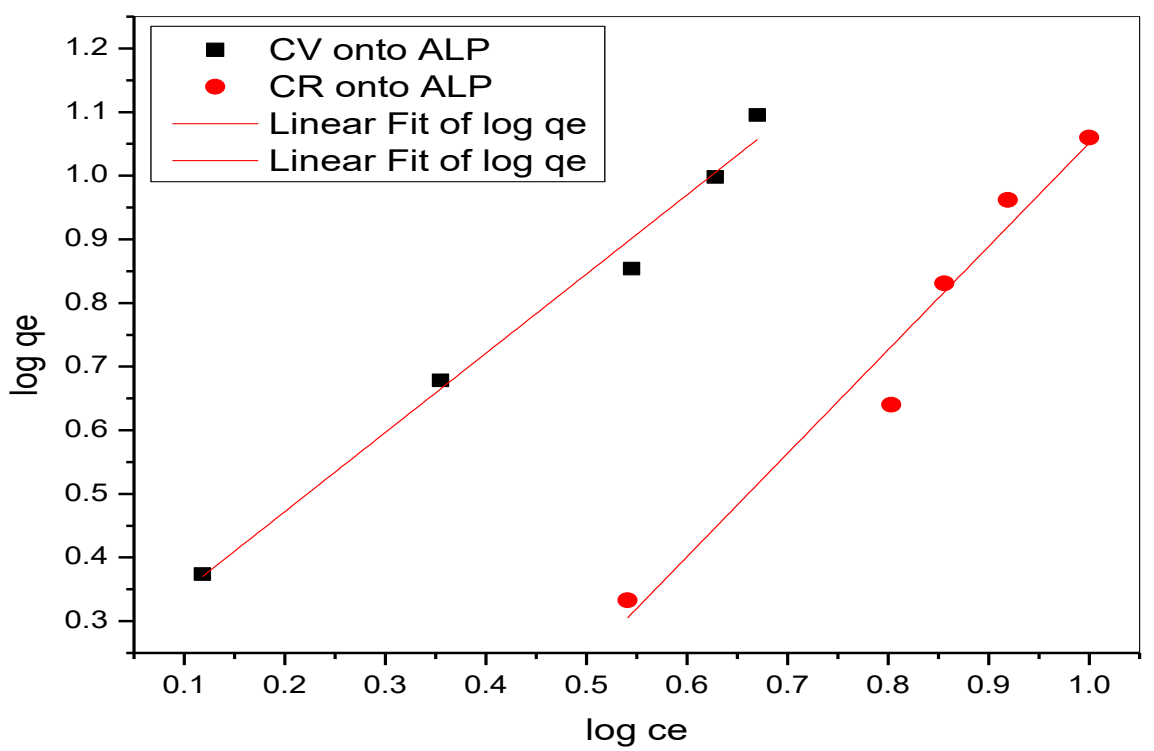

Fig. 9: Freundlich isotherm plot for the adsorption of CV and CR onto ALP

Fig. 8, and Fig. 9, show the Langmuir and freundlich adsorption model plot for the adsorption of $\mathrm{CV}$ and CR onto ALP respectively. The isotherm parameter and $\mathrm{R}^{2}$ values are summarized in Table 1 . Based on the values of correlation coefficient $\left(R^{2}\right)$ (Table 1$)$ the Langmuir plot was inadequate in describing the adsorption processes. The experimental data fitted well with the Freundlich isotherm model, hence, indicating the adequacy of the Freundlich isotherm to describe the adsorption of CV and CR onto ALP and such adsorptions mainly occurred on the heterogeneous surface of the almond leaves powder. Furthermore, Freundlich isotherm constant, $n$, (Table 1) was found to be less than 1 indicating that the adsorption of CV and CR by ALP is a chemical process $[19,24]$. 
Table 1: Isotherm Parameters and values of correlation coefficient for $\mathrm{CV}$ and $\mathrm{CR}$ adsorption

\begin{tabular}{lcccccc} 
& \multicolumn{2}{c}{ Langmuir } & \multicolumn{3}{c}{ Freundlich } \\
\cline { 2 - 7 } & $\begin{array}{c}\mathrm{q}_{\max } \\
\{\mathrm{mg} / \mathrm{g}\}\end{array}$ & $\mathrm{K}_{\mathrm{L}}$ & $\mathrm{R}^{2}$ & $\mathrm{n}$ & $\begin{array}{c}\mathrm{K}_{\mathrm{f}} \\
\{\mathrm{mg} / \mathrm{g})(\mathrm{L} / \mathrm{mg})\end{array}$ & $\mathrm{R}^{2}$ \\
\hline CV onto ALP & 22.957 & 0.072 & 0.072 & 0.803 & 1.672 & 0.984 \\
CR onto ALP & 7.772 & 0.062 & 0.062 & 0.615 & 0.267 & 0.955
\end{tabular}

\section{Adsorption Kinetics}

The Pseudo-first-order kinetic mode is represented by

$$
\log \left(q_{e}-q_{t}\right)=\log q_{e}-\frac{k 1}{2.303} t,
$$

were $\mathrm{q}_{\mathrm{e}}$ and $\mathrm{q}_{\mathrm{t}}$ are the values of amount of the dye adsorbed per unit mass on the adsorbent at equilibrium and at various time $\mathrm{t}$, respectively, $\mathrm{k}_{1}$ is the Pseudo-first-order adsorption rate constant $\left(\mathrm{min}^{-1}\right)$. The values of $\mathrm{k}_{1}$ and calculated $\mathrm{q}_{\mathrm{e}}$ can be determined from the slope and intercept respectively, of the linear plot of $\log \left(\mathrm{q}_{\mathrm{e}}-\mathrm{q}_{\mathrm{t}}\right)$ versus $\mathrm{t}$.

The pseudo-second-order kinetic model is expressed by

$$
\frac{\mathrm{t}}{\mathrm{q}_{\mathrm{t}}}=\frac{1}{\mathrm{k}_{2} \mathrm{q}_{\mathrm{e}}^{2}}+\frac{1}{\mathrm{q}_{\mathrm{e}}} \mathrm{t}
$$

where $\mathrm{k}_{2}$ is the pseudo-second-order adsorption rate constant $(\mathrm{g} / \mathrm{mg} / \mathrm{min})$ and $\mathrm{q}_{\mathrm{e}}$ is the amount of dye adsorbed $(\mathrm{mg} / \mathrm{g})$ on the adsorbent at equilibrium.

The initial adsorption rate, $\mathrm{h}\left(\mathrm{mg} \cdot \mathrm{g}^{-1} \cdot \mathrm{min}^{-1}\right)$ is expressed as:

$$
\mathrm{h}=\mathrm{k}_{2} \mathrm{q}_{\mathrm{e}}^{2}
$$

The plot of $\mathrm{t} / \mathrm{q}_{\mathrm{t}}$ versus gives a linear relationship which allows computation of $\mathrm{k}_{2}, \mathrm{~h}$ and calculated qe..

Among these models, the criterion for their applicability is based on judgment on the respective correlation coefficient $\left(\mathrm{R}^{2}\right)$ and agreement between experimental and calculated value of $\mathrm{q}_{\mathrm{e}}[9,25]$.

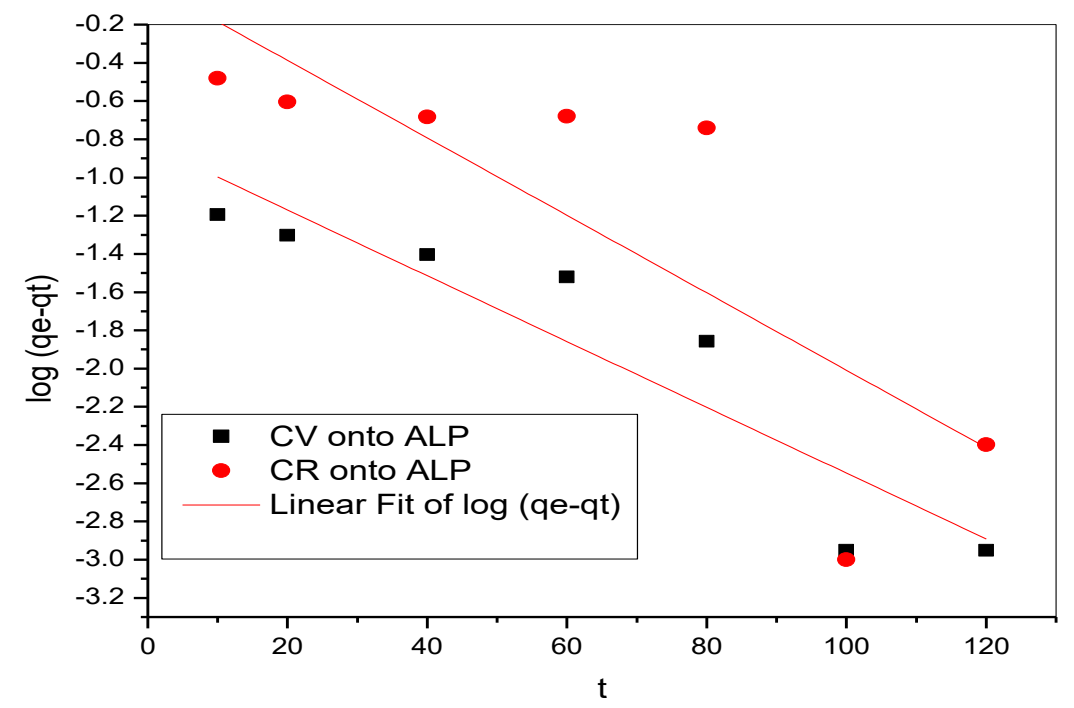

Fig. 10: Pseudo first order kinetic plot for the adsorption of CV and CR onto ALP 


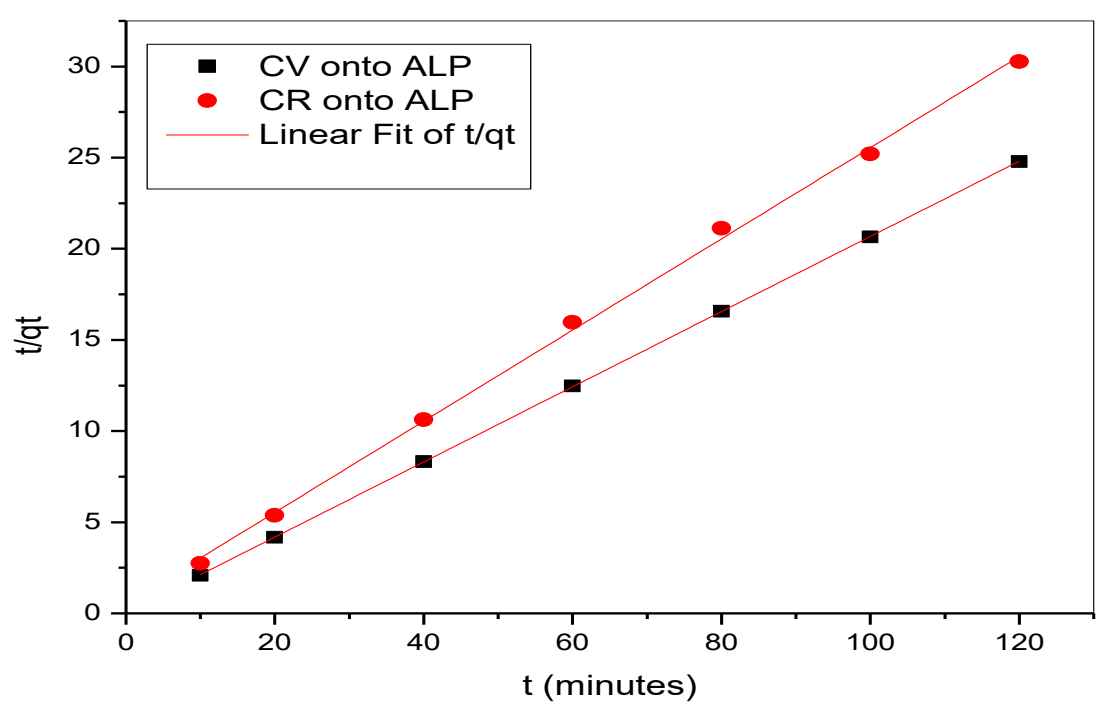

Fig. 11: Pseudo second order kinetic plot for the adsorption of CV and CR onto ALP

Fig. 10 and Fig 11 depict the pseudo-first-order kinetics and pseudo-second-order kinetics for the adsorption of $\mathrm{CV}$ and CR onto ALP. The pseudo-first-order rate constant $\left(\mathrm{K}_{1}\right)$ and $\mathrm{q}_{\mathrm{e}}$ determined from the model are presented in Table 2. It is observed from Fig. 10 that the relationship between the dye solution diffusivity, $\log \left(\mathrm{q}_{\mathrm{e}}-\mathrm{q}_{\mathrm{t}}\right)$ against $\mathrm{t}$ is non-linear. It is also observed (from Table 2) that the calculated $\mathrm{q}_{\mathrm{e}}$ values did not agree with the experimental $\mathrm{q}_{\mathrm{e}}$ since the calculated $\mathrm{q}_{\mathrm{e}}$ values were neither equal nor reasonably close to the experimental $\mathrm{q}_{\mathrm{e}}$ values. Therefore, pseudofirst-order model was inadequate in representing the adsorption of CV and CR onto ALP.

The pseudo-second-order rate constant $\mathrm{K}_{2}$, and $\mathrm{q}_{\mathrm{e}}$ determined from the model are presented in Table 2. It can be observed from Table 2, that there is a good agreement between the calculated $\mathrm{q}_{\mathrm{e}}$ value and the experimental $\mathrm{q}_{\mathrm{e}}$ value i.e. $\mathrm{q}_{\mathrm{e}}\left(\mathrm{cal}\right.$.) and $\mathrm{q}_{\mathrm{e}}$ (exp.) for the adsorption of CV and CR onto ALP. It is therefore evident that pseudo-second-order is the best fitted kinetic model and is therefore very adequate in describing and representing the kinetics of the adsorption of $\mathrm{CV}$ and $\mathrm{CR}$ onto ALP. Hence the adsorption process may be controlled by chemisorptions and it played a significant role in the rate determining step [26, 27]. This also indicates that the forming of interaction between the adsorbates ( $\mathrm{CV}$ and $\mathrm{CR}$ ) and adsorbent on the external surface of the adsorbent is the rate limiting step [18].

Table 2: Pseudo-first order and second order kinetic model parameters for CV and CR adsorption

$$
\text { Pseudo-First Order Model Pseudo-Second Order Model }
$$

\begin{tabular}{lcccccccc} 
& $\begin{array}{c}\mathrm{q}_{\mathrm{e}}(\mathrm{exp}) \\
\{\mathrm{mg} / \mathrm{g}\}\end{array}$ & $\begin{array}{c}\mathrm{k}_{1} \\
\left\{\mathrm{~g} \cdot \mathrm{mg}^{-}\right. \\
\left.{ }^{1} \mathrm{~min}^{-1}\right\}\end{array}$ & $\begin{array}{c}\mathrm{q}_{\mathrm{e}}(\mathrm{cal}) \\
\{\mathrm{mg} / \mathrm{g}\}\end{array}$ & $\mathrm{R}^{2}$ & $\begin{array}{c}\mathrm{h} \\
\left\{\mathrm{mg} \cdot \mathrm{g}^{-}\right. \\
\left.\mathrm{Imin}^{-1}\right\}\end{array}$ & $\begin{array}{c}\mathrm{K}_{2} \\
\left\{\mathrm{~g} \cdot \mathrm{mg}^{-}\right. \\
\left.\mathrm{min}^{-1}\right\}\end{array}$ & $\begin{array}{c}\mathrm{q}_{\mathrm{e}}(\mathrm{cal}) \\
\{\mathrm{mg} / \mathrm{g}\}\end{array}$ & $\mathrm{R}^{2}$ \\
\cline { 2 - 8 } $\mathrm{CV}$ & 4.842 & 0.040 & 0.149 & 0.837 & 16.76 & 0.713 & 4.850 & 0.9999 \\
$\mathrm{CR}$ & 3.969 & 0.047 & 1.043 & 0.591 & 1.86 & 0.116 & 3.998 & 0.998 \\
\hline
\end{tabular}

\section{Adsorption Thermodynamics}

The thermodynamic parameters such as change in Gibb's free energy $\left(\Delta \mathrm{G}^{0}\right)$, change in enthalpy $\left(\Delta \mathrm{H}^{0}\right)$ and change in entropy $\left(\Delta \mathrm{S}^{0}\right)$ for the adsorption of the dyes onto ALP have been determined using the following equations: 
The Gibb's free energy, $\Delta \mathrm{G}$, equation is expressed as follows [28, 29],

$$
\Delta \mathrm{G}=-\mathrm{RT} \ln \mathrm{K}_{\mathrm{ads}}
$$

The equilibrium constants ( $K a d s$ ) were calculated according to the following equation:

$$
K_{\text {ads }}=\frac{\text { Dye concentration on the solid (adsorbent)at equilibrium }\left(q_{e}^{m}\right)}{\text { Dye concentration in solution at equilibrium }\left(C_{e}\right)}
$$

The Van't Hoff equation is expressed as follows:

$$
\ln K_{a d s}=\frac{\Delta S^{0}}{R}-\frac{\Delta H^{0}}{R T}
$$

where $R$ is gas constant, $T$ is absolute temperature in Kelvin, $\Delta S^{0}$ and $\Delta H^{0}$ are entropy and enthalpy respectively. The plot of $\ln K_{a d s}$ versus $1 / T$ gives a linear relationship, which allows the computation of $\Delta H$ and $\Delta S$ values from the slope and intercept respectively.

Fig. 12 depicts the linear Van't Hoff equation plot for the adsorption of CV and CR onto ALP.

Negative $\Delta G^{0}$ values obtained at all temperatures (Tables 3 and 4) indicate the feasibility and the spontaneous nature of $\mathrm{CV}$ and $\mathrm{CR}$ dyes adsorption onto ALP. It can also be observed from Table 3 and 4, which the values of $\Delta G$ for the adsorption of CV and CR onto ALP decreased with increase in temperature. This indicates a rapid and more spontaneous adsorption at the lower temperature of the adsorption process [29].

The positive $\Delta \mathrm{H}^{0}$ values obtained for the adsorption of both dyes confirm the endothermic nature of the adsorption processes. While the positive values of $\Delta \mathrm{S}^{0}$ reveal increased randomness at the solid/solution interfaces during the adsorption of CV and CR onto ALP [22, 26].

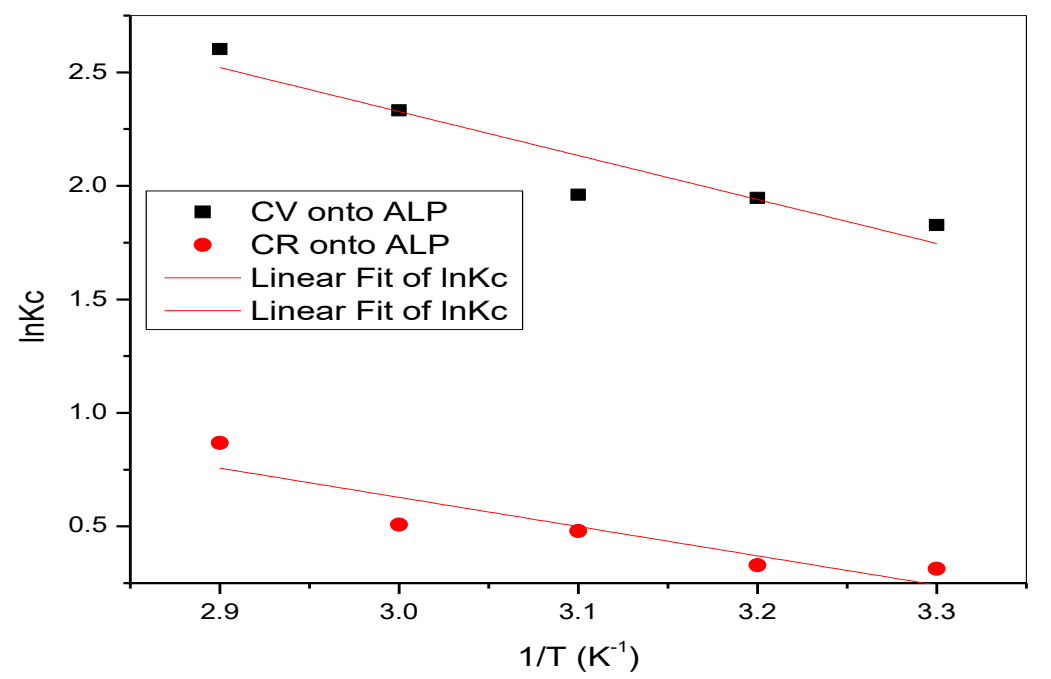

\begin{tabular}{|c|c|c|c|}
\hline $\begin{array}{c}\mathrm{T} \\
(\mathrm{K})\end{array}$ & $\begin{array}{c}\Delta \mathrm{G} \\
(\mathrm{KJ} / \mathrm{mol} . \mathrm{K})\end{array}$ & $\begin{array}{c}\Delta \mathrm{H} \\
(\mathrm{KJ} / \mathrm{mol} . \mathrm{K})\end{array}$ & $\begin{array}{c}\Delta S \\
(\mathrm{~J} / \mathrm{mol} . \mathrm{K})\end{array}$ \\
\hline 303 & -4601.12 & \multirow{5}{*}{16.106} & \multirow{5}{*}{67.667} \\
\hline 313 & -5064.76 & & \\
\hline 323 & -5266.58 & & \\
\hline 333 & -6456.53 & & \\
\hline 343 & -7420.56 & & \\
\hline
\end{tabular}

Fig.12: Van't Hoff plot for the adsorption of CV and CR onto ALP

Table 3: Thermodynamic data and parameter for CV adsorption onto ALP 
Table 4: Thermodynamic data and parameter for CR adsorption onto ALP

\begin{tabular}{|c|c|c|c|}
\hline $\mathrm{T}$ & $\begin{array}{c}\Delta \mathrm{G} \\
(\mathrm{KJ} / \mathrm{mol} . \mathrm{K})\end{array}$ & \multirow{\mathrm{KJ}}{\Delta}{$/ \mathrm{mol} . \mathrm{K})$} & $\begin{array}{c}\Delta \mathrm{S} \\
\mathrm{J} / \mathrm{mol} . \mathrm{K})\end{array}$ \\
\hline 303 & -788.312 & & \\
\cline { 1 - 2 } 313 & -854.91 & \multirow{2}{*}{10.481} & \multirow{2}{*}{37.340} \\
\cline { 1 - 2 } 323 & -1287.32 & & \\
\hline 333 & -1404.81 & & \\
\hline 343 & -2473.51 & & \\
\hline
\end{tabular}

\section{Conclusions}

The potential of almond leaves (ALP) powder as an effective adsorbent for the removal of crystal violet $(\mathrm{CV})$ and Congo red (CR) dye from aqueous medium has been identified. The adsorption of CV and CR onto ALP powder was found to be influenced by contact time, adsorbent dose, initial concentration, temperature and initial $\mathrm{pH}$ of the solution. The optimum adsorption of $\mathrm{CV}$ and $\mathrm{CR}$ dyes was found at $\mathrm{pH} 10$ and 2 respectively. Maximum adsorption capacity was $22.957 \mathrm{mg} / \mathrm{g}$ and $7.772 \mathrm{mg} / \mathrm{g}$ at $50 \mathrm{mg} / \mathrm{L}$ initial $\mathrm{CV}$ and $\mathrm{CR}$ dye concentration respectively. Temperature had strong influence on the adsorption processes and the maximum removal was observed at $343 \mathrm{~K}$ and $333 \mathrm{~K}$ for $\mathrm{CV}$ and $\mathrm{CR}$ dyes respectively. The equilibrium was attained at $100 \mathrm{~min}$ for the adsorption of $\mathrm{CV}$ and $\mathrm{CR}$ dyes. The kinetic studies revealed that the adsorption of $\mathrm{CV}$ and CR dyes onto ALP followed the pseudo-second-order kinetic model. The study on equilibrium sorption revealed that Freundlich isotherm model gave the best fit to the experimental data. The calculated thermodynamic parameters such as negative $\Delta G$ and positive $\Delta H$ values obtained indicated a spontaneous and endothermic nature of the adsorption of CV and CR dyes onto ALP powder respectively. While the positive $\Delta \mathrm{S}$ values obtained for both adsorption of $\mathrm{CV}$ and $\mathrm{CR}$ indicated increase in randomness during the adsorption process. The present results confirm the use of ALP powder as an inexpensive and efficient adsorbent without any pretreatment or modification for the removal of Crystal violet and Congo red dyes from aqueous solutions and waste effluents.

\section{References}

[1] O. Siew-Teng et al., Equilibrium studies and kinetics mechanism for the removal of basic and reactive dyes in both single and binary systems using EDTA modified rice husk, Intl. J. Physical Sci. 5(5) (2010) 582-595.

[2] A. Riccardo et al., Adsorption of congo red dye on hazelnut shells and degradation with phanerochaete chrysospruim, Bio. Resources. 3(4) (2008) 1146-1155.

[3] F. Ferrero, Dye removal by low cost adsorbents: Hazelnut shells in comparison with wood saw dust, J. Mat. 142 (2007) 144-152.

[4] C.R.T. Bertolini et al., Adsorption of crystal violet from aqueous solution onto Zeolites from coal fly and bottom ashes, Electronic Journal of Chemistry. 5(3) (2013) 179-191.

[5] R. Han et al., Use of rice husk for adsorption of congo red from aqueous solution in column mode, Bioresource Technol. 99 (2008) 2938-2946.

[6] C. Sudipta et al., Adsorption of congo red by chitosan hydrogel beads impregnated with carbon nanotubes, Bioresource Technology. 101 (2010) 1800-1806.

[7] G. Crini, Non-conventional low-cost adsorbents for dye removal: a review, J. Bioreso. Technol. 97 (2006) 1062-1070.

[8] R. Malik, D.S. Rametke, S.R. Wate, Adsorption of malachite green on groundnut shell waste based powdered activated carbon, J. Was. Manag. 27 (2006) 1-8.

[9] N. Sharma, B.K. Nnadi, Utilization of sugarcane baggase, an agricultural waste to remove malachite green dye from aqueous solution, J. Mater. Environ. Sci. 4(6) (2013) 1052-1065.

[10] K.S. Bharathi, S.T. Ramesh, Removal of dyes using agricultural waste as low-cost adsorbents: A review, Appl.Water Sci. 3 (2013) 773 -790. 
[11] S.K. Bajpai, A. Jain, Equilibrium and thermodynamic studies for adsorption of crystal violet onto spent tea leaves, Water. 4 (2012) 52-71.

[12] M. Alshabanat, G. Alsenani, R. Almufarij, Removal of crystal violet dye from aqueous solutions onto date palm fiber by adsorption technique, Journal of Chemistry. (2013) 1-6.

[13] W.C. Wanyonyi, J.M. Onyari, P.M. Shiundu, Adsorption of congo red dye from aqueous solutions using roots of Eichhornia crassipes: Kinetic and equilibrium studies, Energy Procedia, 50 (2014) 862-869.

[14] G.K. Nagda, V.S. Ghole, Biosorption of congo red by hydrogen peroxide treated tendu waste, Iran. J. Environ. Health Sci. Eng. 6(3) (2009) 195-200.

[15] M.C.S. Reddy, L. Sivaramakrishna, V.A. Reddy, The use of an agricultural waste material Jujuba seeds for the removal of anionic dye (Congo red) from aqueous solution, J. Hazard. Mater. 203-204 (2012) 118-127.

[16] G.C. Panda, S.K. Das, A.K. Guha, Jute stick powder as a potential biomas for the removal of congo red and rhodamine B from aqueous solution, J. Hazard. Mater. 164 (2009) 374-379.

[17] M.L. Gary et al., Spectroscopy: Infrared spectroscopy, $4^{\text {th }}$ ed., Brooks/Cole, Bellingham, Washington, 2010, pp. 15-87.

[18] C. Umpuch, B. Jutarat, Adsorption of organic dyes from aqueous solution by surfactant modified corn straw, Inter. J. Chem. Eng. Applications. 4(3) (2013) 134-139.

[19] P.S. Kumar et al., Adsorption of basic dye onto raw and surface-modified agricultural waste, Env. Progress and Sustainable Energy. 33(1) (2013) 87-98.

[20] M.H. Baek et al., Removal of malachite green from aqueous solution using degreased coffee bean, J. Hazard. Mater. 176 (2010) 820-828.

[21] A. Ozcan et al., Modification of bentonite with a cationic surfactant: An adsorption study of textile dye Reactive Blue 19, J. Hazard Mater. 140 (2007) 173-179.

[22] R. Ahmad, R. Kumar, Adsorptive removal of Congo red dye from aqueous solution using bael shell carbon, Appl. Surf. Sci. 257 (2010) 1628-1633.

[23] T.F. Hassanein, B. Koumanova, Evaluation of adsorption potential of the agricultural waste wheat straw on basic yellowish 21, Journal of the University Chemical Technology and Metallurgy. 45(4) (2010) 407-414.

[24] G. Mckay, M.S. Otterbum, A.G. Sweetney, The removal of colour from effluent using various adsorbents, III Silica rate process, Water Research. 14 (1981) 14-20.

[25] P. Satish et al., Kinetics of adsorption of crystal violet from aqueous solutions using different natural materials, Inter. J. Env. Sci. 1(6) (2011) 1116-1134.

[26] T.L. Seey, M.J. Noordin, M. Kassim, Acidic and basic dyes removal of adsorption on chemically treated mangrove barks, Inter. J. Appl. Sci. Techno. 2(3) (2012) 270-276.

[27] H. Kaur, A. Thakur, Adsorption of congo red dye from aqueous solution onto ash of Cassia fistula seeds: Kinetic and thermodynamic studies, Chem. Sci. Rev. Lett. 3 (2014) 159-169.

[28] P. Donghee, Y. Yeoung-sang, M.P. Jong, The fast, present and future trends of biosorption, Biotechnology and Bioprocessing Engineering. 15 (2010) 86-102.

[29] Z.L. Yaneva, N.V. Georgieva, Insights into congo red adsorption on agro-industrial materials: Spectral, equilibrium, kinetic, thermodynamic, dynamic and desorption studies: A review, International Review of Chemical Engineering. 4(2) (2012) 127-146. 